\title{
MODAL MANUSIA DALAM PERSPEKTIF ISLAM HUBUNGANNYA DENGAN KINERJA PERUSAHAAN
}

\author{
Nurrohman \\ Program Magister Ekonomi Islam UIN Sunan Gunung Djati Bandung \\ Email: anour.rohman@gmail.com
}

\begin{abstract}
In this paper discusses the emphasis of Islamic principles on variables that are already popular in the conventional view. It seems to have been overlooked and forgotten by Muslim owner-managers even though they are important and valuable elements of Islamic human capital that they rarely adopt in their business operations. These variables are motivation, knowledge, experience and business training. The writing of this article uses the literature survey method. Use of this method by utilizing library resources in obtaining data, tracking previous sources to prepare theoretical frameworks and sharpening methodologies. The principles held by an Islamic human capital in addition to increasing productivity in achieving maximum corporate profits also get the blessing of Allah Almighty through the work he is doing.

Keyword: Company Performance, Human Capital, Quality Of Work
\end{abstract}

\begin{abstract}
ABSTRAK
Dalam tulisan ini membahas Penekanan prinsip dan nilai ajaran islam pada variabel-variabel yang sudah populer dalam pandangan atau kajian konvensional. Tampaknya sudah terabaikan dan terlupakan oleh manajer-pemilik muslim padahal itu semua merupakan unsur penting serta sangat berharga dari sumber daya manusia Islam yang memang jarang di adopsi oleh mereka dalam operasi bisnis yang dijalankannya. Variabel-variabel itu adalah motivasi, pengetahuan, pengalaman dan pelatihan bisnis. Penulisan artikel ini menggunakan metode survei literatur. Penggunaan metode ini dengan memanfaatkan sumber daya perpustakaan dalam memperoleh data, melacak sumber-sumber sebelumnya untuk menyiapkan kerangka kerja teoritis dan mempertajam metodologi. Prinsip-prinsip yang dipegang seorang modal manusia islam selain untuk meningkatkan produktifitas dalam mencapai laba perusahaan yang maksimal juga mendapatkan ridho Allah swt melalui pekerjaan yang sedang dikerjakannya.
\end{abstract}

Kata Kunci: Kinerja Perusahaan, Kualitas Kerja, Modal Sumber Daya Manusia

\section{PENDAHULUAN}

Pada saat ini, banyak organisasi yang menyadari keunggulan konsep bisnis Islam yang perlu diadopsi dalam menjalankan operasi bisnisnya. Petunjuk yang komprehensif dan yang mengarah pada kinerja yang lebih baik dari perusahaan yang tidak ditemukan dalam metode konvensional. Dalam agama Islam terdapat panduan hidup yang lengkap Dari Al-Qur'an dan Sunnah, artinya Islam mengajarkan semua aspek kehidupan dunia dan kehidupan akhirat harus sesuai dengan prinsip-prinsip syari'ah.(Sunaryo, 2017) Dimana aspek dunia pada akhirnya harus menuju kepada aspek akhirat (Ajmain, Fiky, Ruskam, \& Mohamed, 2020) , keduanya sudah terintegrasi dan tidak bisa dipisahkan. Ajaran dalam islam tidak hanya mencari keuntungan yang optimal tetapi juga memaksimalkan kemaslahahatan. Alqur'an dan Hadits adalah sebagai pedoman yang direalisasikan oleh perbuatan dan perkataan Nabi Muhammad sebagai contoh manusia terbaik dalam konsep bisnis Islam serta diakui berpengaruh terhadap kinerja organisasi.

* Copyright (c) 2020 Nurrohman

This work is licensed under a Creative Commons Attribution-ShareAlike 4.0 International License. 
penelitian yang menemukan bahwa tidak ada hubungan antara kegiatan ibadah ritual dan kinerja bisnis dalam hal ini islam berbeda, semua aktivitas termasuk kegiatan bisnis jika dilakukan dengan niat yang baik yaitu bertujuan mendapatkan ridha Allah Swt. Serta sesuai dengan Al-Qur'an dan Hadist maka ini disebut ibadah.

Metode konvensional telah banyak dipakai oleh banyak peneliti dalam melakukan penelitian sumber daya manusia. Banyak bukti dalam penelitian-penelitian bahwa adanya hubungan positif antara pengembangan sumber daya manusia dan kinerja organisasi. Ini mencerminkan sumber daya tidak berwujud (Suherman, 2020), terutama sumber daya manusia sangat berpengaruh terhadap nilai pasar dibandingkan dengan sumber daya berwujud. Jadi, Penekanan pada modal manusia dalam organisasi/perusahaan bisnis lebih diutamakan. Kemampuan dan keterampilan pekerja harus selalu ditingkatkan dengan cara Organisasi harus mendorong pembelajaran individu dan organisasi serta harus menciptakan lingkungan yang mendukung di mana pengetahuan dapat dibuat, dibagikan, dan diterapkan. Kinerja dan pertumbuhan organisasi secara tidak langsung dipengaruhi oleh pelanggaran pada umumnya. Islam mengajarkan sikap dan perilaku etis dari karyawan atau pemilik-manajer harus berdasarkan prinsip-prinsip syari'ah. Ketaatan pada syari'ah akan membawa kebaikan untuk individu dan organisasi.

\section{METODE PENELITIAN}

Penulisan artikel ini menggunakan metode survei literatur. Penggunaan metode ini dengan memanfaatkan sumber daya perpustakaan dalam memperoleh data, melacak sumber-sumber sebelumnya untuk menyiapkan kerangka kerja teoritis dan mempertajam metodologi.(Zed, 2004) Penulis menggunakan tiga jenis literatur yang dirujuk yaitu: literatur sejarah, literatur sumber-sumber ajaran islam, dan literatur ekonomi dan keuangan islam kontemporer. Untuk jenis literatur sejarah, artikel ini akan menjelaskan dan memperdalam jawaban atas pertanyaan yang belum diselesaikan dimasa lalu. Informasi historis baru yang berkaitan dengan subject materi penulisan ini dipandang berpeluang memberikan solusi(Zed, 2004) untuk aspek-aspek yang memerlukan penjelasan lebih lanjut. Dalam pelaksanaannya, semua karya masa lalu, dapat dipandang dalam bingkai studi literatur sejarah. Untuk jenis literatur sumber-sumber ajaran islam, metode yang dianggap sudah baku pada masing-masing bidang kajian dijadikan pegangan studi literatur. Literatur sirah nabawiyah, tafsir, hadits, fiqih dan karya studi islam kontemporer, secara proposional, tetap menggunakan interkoneksi untuk membangun konstruksi baru modal sumber daya islam dalam lintasan sejarah perkembangan ekonomi islam. Titik pemberangkatannya dimulai dari metode Al-Qur'an, sebagai prespektifnya. Metode selanjutnya diambil dari prespektif hadits. Dipilihnya prespektif ajaran Al-Qur'an dan hadits bukan tanpa alasan.

\section{HASIL DAN PEMBAHASAN}

Penelitian-penelitian yang dilakukan oleh beberapa peneliti bahwa motivasi, pelatihan dan pengalaman memiliki pengaruh positif signifikan terhadap kinerja karyawan yang merupakan kinerja perusahaan juga. (Livanda Wenly Umboh, bernhard Tewal, 2016; Octaviana Panambunan, Berhard Tewal, 2017; Octavianus, Manajemen, Sam, \& Manado, 2018; Oktaviani \& Darmo, 2017; R., Khalid, M. A. \& Imam, B., 2014; Situmeang, 2017; Susanto, 2019; Widhianingrum, 2017) Penelitian-penelitian ini memilih beberapa variabel sumber daya manusia diantaranya adalah pelatihan kerja, motivasi dan pengalaman kerja. Analisa yang digunakan oleh peneliti-peneliti tersebut adalah regresi berganda. Penjelasan penelitiannya sebagai berikut: 


\section{Pengalaman kerja atau bisnis}

Pengalaman kerja adalah sesuatu atau kemampuan yang dimiliki oleh para karyawan dalam menjalankan tugas-tugas yang dibebankan kepadanya. (Nyoman, Candra, \& Ardana, 2016) Pengalaman kerja memberikan pengetahuan organisasi spesifik individu yang membantu dalam mengembangkan strategi sukses yang mengarah ke tingkat pertumbuhan yang lebih tinggi atau kinerja organisasi yang lebih baik.

Memiliki pengalaman yaitu di bidang kerja atau bisnis, akan mengajar mereka pada penilaian yang benar dan salah, dan mereka tidak boleh jatuh dalam kesalahan yang sama yang mereka lakukan sebelumnya. Ini selaras dengan sebuah hadits yang diriwayatkan oleh Abu Hurairah menyatakan bahwa 'seorang mukmin dilarang jatuh kepada lubang yang sama hingga dua kali'.(Hasanah, 2018) telah dijelaskan bahwa Islam mencari pengalaman kerja atau bisnis sebagai faktor yang secara signifikan mempengaruhi pertumbuhan perusahaan atau kinerja organisasi. Selaras dengan penelitian yang dilakukan oleh (Livanda Wenly Umboh, bernhard Tewal, 2016; Nyoman et al., 2016; Octaviana Panambunan, Berhard Tewal, 2017; Octavianus et al., 2018; R., Khalid, M. A. \& Imam, B., 2014; Situmeang, 2017) bahwa pengalaman berpengaruh terhadap kinerja karyawan dengan kata lain berpengaruh terhadap kinerja perusahaan.

\section{Motivasi Islam}

Menurut Hasibuan (2010, hal. 95) motif adalah suatu perangsang keinginan (want) dan daya penggerak kemauan bekerja seseorang; setiap motif mempunyai tujuan tertentu yang ingin dicapai. Sedangkan motivasi adalah pemberian daya penggerak yang menciptakan kegairahan kerja sesorang, agar mereka mau bekerja sama, bekerja efektif dan terintegrasi dengan segala daya upayanya untuk mencapai kepuasan. Menurut Rivai (2010, hal. 837) , motivasi adalah "serangkaian sikap dan nilai-nilai yang mempengaruhi individu untuk mencapai hal yang spesifik sesuai dengan tujuan individu".

Menurut ajaran islam motivasi adalah sama dengan niat. islam menjelaskan, bahwa setiap pekerjaan atau amal harus diawali dengan (niat).(Ayep Rosidi, 2017) Niat ini menentukan amal seorang pekerja muslim yang akan berdampak pada tindakan atau perilaku positif atau negatif. Niat tergambar berdasarkan pada keyakinan atau kepercayaan. Keyakinan dalam islam mengacu pada tauhid. Pekerja Muslim harus sadar akan keberadaan Allah, bahwa Allah menyaksikan setiap pekerjaanya dan ini yang akan membawa niatnya kearah yang positif. Pekerja Muslim menemukan faktor motivasi sebagai aspek yang sangat penting seperti yang dinyatakan dalam ajaran agama dibandingkan dengan agama lain.

Ahmad (2014) mengemukakan bahwa motivasi dalam perspektif manajemen Islam berbeda dari teori lain. Pengusaha Muslim sebagai pemegang amanah (dapat dipercaya) di bumi memiliki keyakinan mendasar dan harus menyadari hal-hal berikut; (i) Muslim berkewajiban untuk mencari secara komersial sebanyak yang mereka bisa atau mengambil lebih banyak peluang bisnis, untuk karunia ALLAH SWT yang telah menyediakan makanan; (ii) bekerja sebagai bentuk amal saleh (amal salih); (iii) bekerja sebagai bentuk perbudakan kepada Allah SWT dengan kesesuaian dengan norma dan nilai-nilai Ilahi; (iv) hadiah atas perbuatan baik di dunia ini dan akhirat.

Pekerjaan-pekerjaan yang baik serta bermanfaat sangat dianjurkan bahkan diperintahkan oleh ajaran islam sehingga pekerjaan yang dilakukan oleh seorang mukmin akan memberikan nilai tambah juga derajat manusia dapat terangkat baik secara individu maupun kelompok. sesuai dengan yang di firmankan Allah dalam al-qur'an surat al-an'am ayat 132 yaitu: "Dan masing-masing orang memperoleh derajat-derajat (seimbang) dengan apa yang dikerjakannya." perintah dan anjuran islam akan membawa kepada hal-hal atau tindakan-tindakan yang akan membawa keberhasilan organisasi. Dari penelitian- 


\section{Khazanah Sosial, Vol. 2 No. 1: 31-36}

Modal manusia dalam prespektif Islam hubungannya dengan Kinerja Perusahaan Nurrohman

penelitian sebelumnya menyebutkan bahwa motivasi berpengaruh pada kinerja karyawan sekaligus kinerja perusahaan atau organisasi. (Oktaviani \& Darmo, 2017; R., Khalid, M. A. \& Imam, B., 2014; Susanto, 2019; Widhianingrum, 2017)

\section{Pelatihan Kerja Islam}

Pelatihan adalah penggunaan yang sistematis dan terencana. kegiatan pelatihan berguna untuk meningkatkan pembelajaran. Pendekatan itu dapat diringkas dalam ungkapan pelatihan berbasis pelajar. Ini adalah salah satu dari beberapa tanggapan organisasi dapat melakukan upaya untuk mempromosikan pembelajaran. (Octavianus et al., 2018)

Pelatihan-pelatihan yang diadakan organisasi bagi para pekerja akan meningkatkan kualitas pekerjaanya. Islam mengajarkan beramal atau bekerja harus dengan ihsan. ihsan yaitu mengerjakan sesuatu harus dengan sebaik-baiknya. Dengan adanya perintah atau anjuran ini maka bagi pekerja muslim yang baik maka harus mengadakan pelatihan-pelatihan.

Dalam pandangan Islam, Altalib (1991) mengemukakan bahwa pelatihan Islam mencakup semua dari peningkatan moral dan spiritual manusia dan akhirnya terwujud menjadi perkembangan fisik. Pelatihan dan pengembangan harus dilakukan untuk meningkatkan iman kepada Allah SWT. Pelatihanpelatihan yang diadakan oleh organisasi ini diharapkan mampu meningkatkan pengetahuan, keamampuan, keahlian agar bisa meningkatkan pula kualitas kerja dari seorang karyawan dan pekerja tersebut.

Muslim juga memiliki tanggung jawab untuk melakukan level terbaik mereka untuk mendapatkan kesempurnaan dan keunggulan dalam ibadah dan semua karya kehidupan. Dari literatur yang disebutkan di atas, jelas bahwa Islam mendorong Muslim untuk menghadiri pelatihan berdasarkan syariah yang terdiri dari program spiritual dan komersial yang diharapkan akan mempengaruhi kinerja perusahaan. Ajaran islam tentang mengerjakan sesuatu harus dengan sebaik-baiknya dengan cara memperbanyak latihan maka ini selaras dengan penelitian-penelitian yang dilakukan oleh (Livanda Wenly Umboh, bernhard Tewal, 2016; Nyoman et al., 2016; Octaviana Panambunan, Berhard Tewal, 2017; Octavianus et al., 2018; Oktaviani \& Darmo, 2017; R., Khalid, M. A. \& Imam, B., 2014) bahwa pelatihan berpengaruh positif serta signifikan terhadap kinerja pegawai yang mana sama dengan berpengaruh terhadap perusahaan atau organisasi.

\section{SIMPULAN}

Dapat disimpulkan dari tinjauan literatur dan penelitian-penelitian yang dilakukan sebelumnya bahwa apa yang menjadi kualitas etik kerja modal manusia dari prespektif Islam berhubungan positif. Diantaranya Islam mengajarkan tentang bekerja harus baik dan bermanfaat ini merupakan motivasi yang sangat diperlukan oleh sumber daya manusia khususnya kualitas modal manusia itu sendiri. Sehingga dengan adanya motivasi yang seperti ini akan mempengaruhi kualitas kinerja perusahaan menjadi lebih baik.

Al-qur'an menyebutkan bahwa manusia ada dalam kerugian apabila tidak memanfaatkan waktu dengan baik. Waktu ini apabila dimanfaatkan oleh karyawan atau pekerja dengan sebaik-baiknya dapat mengukir prestasi yang cemerlang dan ini dapat dijadikan pengalaman yang baik. Dimana organisasi/perusahaan bisnis membutuhkan orang-orang yang berpengalaman yang mempunyai prestasi yang bagus. Karena dengan adanya pengalaman-pengalaman yang baik akan meningkatkan kinerja perusahaan. 
Pelatihan-pelatihan bertujuan untuk mendapatkan pekerjaan yang lebih baik wajib dilakukan karena dalam Al-qur'an Allah memerintahkannya. Merupakan suatu kerugian apabila Prestasi yang didapat hari ini menurun daripada prestasi yang didapat hari kemarin, Rasulullah mengajarkan bahwa melakukan yang lebih baik ketika membalas kebaikan-kebaikan yang dilakukan oleh orang lain terhadapnya. Bahkan, idealnya Allah mengajarkan didalam Al-qur'an surat Fushilat ayat 34 dan an-naml ayat 125 seorang mukmin harus tetap berbuat dan beramal yang lebih baik serta bermanfaat, bahkan ketika membalas keburukan yang dilakukan oleh orang lain terhadapnya.

Berbeda dengan metode konvensional, ajaran Islam menyoroti pentingnya pengembangan sumber daya manusia untuk meningkatkan kualitas modal manusia itu sendiri dan hubungannya dengan kinerja perusahaan bisnis. Jelas dengan kualitas etik kerja yang dilakukan oleh setiap orang akan mempunyai kualitas modal manusia yang baik yang oleh karena itu, berpengaruh kepada kinerja perusahaan bisnis. Studi ini memberikan bukti tambahan bahwa sumber daya manusia Islam berhubungan positif dengan kinerja perusahaan.

\section{DAFTAR PUSTAKA}

Ajmain, M. T., Fiky, W. A. R. W. I., Ruskam, A., \& Mohamed, A. K. (2020). Maqasid Keamanan Dan Implikasinya Dalam Pembinaan Sebuah Tamadun. Politicon: Jurnal Ilmu Politik, 2(1), 1-12. Altalib, H. (1991). Training Guide For Islamic Workers. Herndon.

Ayep Rosidi. (2017). Niat Menurut Hadis Dan Implikasinya Terhadap Proses Pembelajaran. Jurnal Inspirasi, Vol. 1(No. 1), 39-50.

Hasanah, A. N. (2018). Seorang Mukmin Tidak Akan Melakukan Kesalahan Yang Sama.

Hasibuan, M. (2010). Organisasi Dan Motivasi Dasar Peningkatan Produktivitas (7th Ed.). Jakarta: Pt. Bumi Aksara.

Livanda Wenly Umboh, Bernhard Tewal, A. (2016). Pengaruh Disiplin, Pelatihan, Pengalaman Dan Lingkungan Kerja Terhadap Prestasi Kerja Karyawan Pt. Enseval Putera Mega Trading Manado. 4(1), 566-574.

Nyoman, N., Candra, W., \& Ardana, I. K. (2016). Pengaruh Pengalaman Kerja, Pendidikan Dan Pelatihan Terhadap Pengembangan Karir Di Pt. Pln (Persero) Distribusi Bali. E-Jurnal Manajemen Unud, 5(9), 5839-5867.

Octaviana Panambunan, Berhard Tewal, I. T. (2017). Pengalaman Kerja, Pelatihan Kerja, Iklim Organisasi Dan Pengaruhnya Terhadap Kinerja Pegawai Pt. Pln (Persero) Wilayah Suluttenggo. Emba, 5(2), 2183-2192.

Octavianus, W. R., Manajemen, J., Sam, U., \& Manado, R. (2018). Pengaruh Pengalaman Kerja Dan Pelatihan Kerja Terhadap Kinerja Karyawan Pt. Telkom Indonesia Cabang Manado. Emba, 6(3).

Oktaviani, E., \& Darmo, I. S. (2017). Pengaruh Pelatihan Dan Motivasi Kerja Terhadap Kinerja Pegawai Sekretariat Direktorat Jenderal Pengelolaan Pembiayaan Dan Risiko Kementerian Keuangan. Jrmb, 2(3), 373-380.

R., Khalid, M. A. \& Imam, B., A. (2014). Islamic Human Capital And Firm Performance: An Evidence Of Small And Medium Enterprises In Bahrain. International Journal of Business And Management, 9(4), 173-181.

Rivai, V. \& E. J. S. (2010). Manajemen Sumber Daya Manusia Untuk Perusahaan (Kedua). Jakarta: Pt. Rajagrafindo Persada.

Situmeang, R. R. (2017). Pengaruh Pengawasan Dan Pengalaman Kerja Terhadap Kinerja Karyawan Pada Pt. Mitra Karya Anugrah Rosinta. Ajie, 02(02), 148-160.

Suherman, D. (2020). Evaluasi Dampak Kebijakan Mesin Parkir Elektronik Di Kota Bandung. Politicon: Jurnal Ilmu Politik, 2(1), 75-86. 


\section{Khazanah Sosial, Vol. 2 No. 1: 31-36}

Modal manusia dalam prespektif Islam hubungannya dengan Kinerja Perusahaan Nurrohman

Sunaryo, H. H. \& H. (2017). Pengaruh Etika Kerja Islam Dan Kepuasan Kerja Terhadap Kinerja Karyawan (Dinas Pemberdayaan Perempuan Dan Perlindungan Anak Kab. Kutai Timur). E - Jurnal Riset Manajemenprodi Manajemen, 118-132.

Susanto, N. (2019). Pengaruh Motivasi Kerja, Kepuasan Kerja, Dan Disiplin Kerja Terhadap Kinerja Karyawan Pada Divisi Penjualan Pt Rembaka. Agora, 7(1).

Widhianingrum, W. (2017). Pengaruh Motivasi Terhadap Kinerja Karyawan Bri Syariah Magetan. Jiei, 3(03), 193-198.

Zed, M. (2004). Metode Penelitian Kepustakaan. Jakarta: Yayasan Obor Indonesia. 